\title{
Host Genetic Variants in HLA Loci Influence Risk for Hepatitis B Virus Infection in Children
}

\author{
Jie Fan, ${ }^{1}$ Xin Huang, ${ }^{1}$ Juan Chen, ${ }^{2}$ Yiling Cai, ${ }^{3}$ Lin Xiong, ${ }^{4}$ Lihong Mu, ${ }^{1,}$ and Li Zhou ${ }^{1,2,}$ \\ ${ }^{1}$ Department of Epidemiology, School of Public Health and Management, Research Center for Medicine and Social Development, Innovation Center for Social Risk \\ Governance in Health, Chongqing Medical University, Chongqing, China \\ ${ }^{2}$ Key Laboratory of Molecular Biology for Infectious Diseases, Institute for Viral Hepatitis, Department of Infectious Diseases, The Second Affiliated Hospital, Chongqing \\ Medical University, Chongqing, China \\ ${ }^{3}$ Obstetrics and Gynecology Department, Chengdu Women and Children's Central Hospital, Sichuan Province, China \\ ${ }^{4}$ Maternal and Child Health Hospital of Chongqing Yuzhong District, Chongqing, China \\ "Corresponding authors: Lihong Mu, Research Center for Medicine and Social Development, Innovation Center for Social Risk Governance in Health, School of Public Health \\ and Management, Chongqing Medical University, Chongqing, China. Tel/Fax: +86-2368485008, E-mail: 1097123703@qq.com; Li Zhou, Research Center for Medicine and Social \\ Development, Innovation Center for Social Risk Governance in Health, School of Public Health and Management, Chongqing Medical University, Chongqing, China. Tel/Fax: \\ +86-2368486780, E-mail: zhouli_tj@163.com
}

Received 2016 March 14; Revised 2016 June 27; Accepted 2016 June 29.

\begin{abstract}
Background: Hepatitis B virus (HBV) infection is a serious public health problem in China and worldwide. Mother-to-child transmission is one of HBV's main transmission routes in highly endemic regions. Genome-wide association studies (GWAS) identify single nucleotide polymorphisms (SNPs) at HLA loci as associated with HBV infection. However, the mechanisms of HBV perinatal transmission and breakthrough in children have not yet been clearly defined.

Objectives: We aimed to explore the association between SNPs at HLA loci and HBV infection and breakthrough in children.

Methods: A total of $274 \mathrm{HBV}$-infected children and 353 controls were selected among children aged between 6 months and 12 years in China. Seven SNPs at HLA-DP and HLA-DQ loci were genotyped to analyze their association with HBV infection in children.

Results: Alleles G in both HLA-DPA1 rs3077 and HLA-DPB1 rs9277535 were found to be significantly associated with HBV infection in children with odds ratios (OR) of 1.309 (95\% CI1.046 to 1.639) and 1.411(95\% CI1.125 to 1.771), respectively. In addition, overdominant analysis found that the rs2281388 (HLADPB1) GA genotype and the rs9366816 (HLA-DPB2) TC genotype were related to HBV infection (rs2281388, OR=1.422, 95\% CI:1.032-1.961; rs9366816, OR= 1.444, 95\% CI:1.045-1.994). Furthermore, this study highlighted that rs9277535 was also significantly associated with HBV breakthrough infection in children whose mothers were positive for hepatitis B surface antigen (HBsAg).

Conclusions: Our study confirmed that genetic variants in HLA-DPA1 and HLA-DPB1 loci have significant associations with HBV infection, especially with HBV breakthrough in children. This study provides insight into HBV infection in children and is valuable for the targeted management of, and control strategies for, this disease.
\end{abstract}

Keywords: Hepatitis B, Single Nucleotide Polymorphism, Breakthrough, HLA

\section{Background}

Hepatitis B (HB) is one of the viruses that attack the liver and can cause both acute and chronic hepatitis, representing a serious public health problem. It is estimated that more than 2 billion people (1/3 of the global population) have been infected with the hepatitis B virus (HBV) worldwide, of whom 360 million are chronic HBV carriers (from $4 \%$ to $6 \%$ of the global population) (1). The possibility of chronic HBV infection depends upon the age at which a person is infected. After HBV exposure, the risk of developing chronic hepatitis $\mathrm{B}(\mathrm{CHB})$ infection is less than $5 \%$ in adults and adolescents; however, for children $<5$ years of age and newborns, the risks are as high as $25 \sim 30 \%$ and 80 90\%, respectively $(2,3)$. Furthermore, from $15 \%$ to $40 \%$ of HBV chronic carriers are expected to progressively develop cirrhosis, hepatocellular carcinoma (HCC) and endstage liver failure (4).

China used to be an area with a high rate of HBV infec- tion and one of the main transmission routes was motherto-child transmission. Since implementing the Expanded Program on Immunization (EPI) in 1992 (this program recommends that all newborns receive three doses of recombination $\mathrm{HB}$ vaccine: $5 \mu \mathrm{g}$ at 0,1 and 6 months), the prevalence of hepatitis B surface antigen (HBsAg) in China has been reduced from $9.8 \%$ in 1992 to $7.2 \%$ in 2006 (5). Although vaccination is effective in preventing vertical transmission, there are still a number of children infected each year. It was reported that approximately $10 \%$ of the children whose mothers were positive for HBsAg and hepatitis B e antigen (HBeAg) did not achieve the protection level and ultimately developed CHB (6).HBV infection is generally attributed to immunological factors, viral factors, environmental factors and host genetic factors. Recently, several genome-wide association studies (GWAS) have reported that genetic variants in the human leukocyte antigen (HLA) are associated with prolonged HBV infection or 
HBV clearance in adults (7). Kamatani et al. (8) and Mbarek et al. (9) demonstrated that single nucleotide polymorphisms (SNPs) at HLA-DPA1, HLA-DPB1, HLA-DQB1 and HLA$D Q B 2$ were strongly associated with chronic HBV infection in Japanese and Korean populations. The association was also proved by Hu et al. (10) and Guo et al. (11) in the Chinese population. However, whether genetic variants in HLA influence the outcome of HBV infection and breakthrough in children still remains unknown. In this study, we aimed to use a case-control study to identify and confirm whether those reported SNPs in adults are related to HBV infection in children.

\section{Objectives}

The aim of this study was to explore the association between SNPs at HLA loci and HBV infection and breakthrough in children.

\section{Methods}

\subsection{Study Subjects}

During October 2013 and May 2015, a total of 627 Han Chinese children were consecutively recruited from the hospital of Chongqing medical university and health center for women and children in Chongqing. Of these children, 274 were HBsAg positive (cases) and 353 were HBsAg negative (controls). Diseased children were included if they were aged from 6 months to 12 years, were HBsAg positive for over 6 months regardless of their alanine aminotransferase (ALT) levels, HBV DNA levels or HBeAg status. Control children were included if they were from the same hospital, were HBsAg negative and had normal serum ALT levels. Subjects with other liver diseases or autoimmune diseases were excluded. Blood samples were collected from the study children and their mothers for further use. Data regarding physical examinations, delivery modes, feeding patterns and HBV vaccination in the study children were obtained from their medical records or questionnaire interviews. The research was conducted according to the guidelines of the world medical association declaration of Helsinki. Written informed consent was obtained from all the subjects in accordance with the study protocol approved by the ethics committee of Chongqing medical university.

\subsection{Laboratory Testing}

HBV markers (HBsAg, HBsAb, HBeAg, HBeAb and HB$\mathrm{cAb}$ ) in the subjects and their mothers were tested by enzyme-linked immunosorbent assay (ELISA). Diagnostic kits were purchased from the Shanghai Kehua bioengineering technology company, limited (Shanghai, China). Human genomic DNA samples were extracted from venous blood samples using a BioTeke DP6101 kit (BioTeke corporation, Beijing, China) according to the manufacturer's instructions. The DNA concentration was measured by Nanodrop2000c spectrophotometer (Thermo Scientific, DE). The eluted DNA was stored at $-80^{\circ} \mathrm{C}$ for further use.

\subsection{SNP Genotyping}

Seven SNPs (rs3077 at HLA-DPA1; rs9277535, rs2281388 and rs3135021 at HLA-DPB1; rs9366816 at HLA-DPB2; rs2856718 at HLA-DQB1; and rs7453920 at HLA-DQB2) were selected in total. Genotyping was performed according to the mass array time-of-flight mass spectrometer (Sequenom company, USA). Polymerase chain reaction (PCR) and extension primers were designed using MassARRAY assay design 3.1 software (Sequenom company, USA). The genotyping procedures were performed according to the manufacturer's iPLEX application guide (Sequenom company, USA). The PCR amplification conditions included an initial precycle incubation of $94^{\circ} \mathrm{C}$ for 15 minutes, followed by 45 cycles of denaturation at $94^{\circ} \mathrm{C}$ for 20 seconds, annealing at $56^{\circ} \mathrm{C}$ for 30 seconds, and extension at $72^{\circ} \mathrm{C}$ for 60 seconds. All the genotyping reactions were performed in 384-well plates. Each plate included four randomly selected duplicates and six negative controls using double distilled water. The average concordance rate for the genotypes was $99.5 \%$.

\subsection{Statistical Analysis}

Statistical analysis was performed with the statistical package for the social sciences (version 17.0, SPSS Inc., Chicago, IL, USA) on a computer. Descriptive statistics (mean, standard deviation and percentage) were conducted to reflect the background characteristics of the participants. Categorical and continuous values were compared by the $\chi^{2}$ test, which was also used for the genetic model analysis. Fisher's exact test was applied when the $\chi^{2}$ test could not be used in certain circumstances. Each component of the model was as follows: allele A versus allele $\mathrm{B}$, $A$ as the major allele, $B$ as the minor allele, dominant model $(A B+B B$ versus $A A)$, recessive model ( $B B$ versus $A B+A A)$, codominant model (AA versus $A B$ versus $B B$ ), and overdominant model ( $A A+B B$ versus $A B)$. The Hardy-Weinberg equilibrium was used to test for the deviation of genotype distribution. Logistic regression was performed for the association between variants in the seven selected SNPs and HBV infection by computing odds ratios (ORs) and 95\% confidence intervals (CIs). A P value $<0.05$ was defined as statistically significant. 


\section{Results}

\subsection{General Characteristics of the Subjects}

Baseline characteristics of the study subjects are provided in Table 1 . A total of 627 subjects ( 361 children were males) were recruited in this study, including 274 patients (90 children were born to HBsAg-positive mothers) and 353 controls (132 children were born to HBsAg-positive mothers). The characteristics of sex, HBIG and HBV vaccination, delivery mode and mother's HBV infection status showed significant differences between the two groups $(\mathrm{P}<0.05)$.

\subsection{Relation of the SNPs and HBV Infection Risk in Children}

The genotype distributions of SNPs were in accordance with the Hardy-Weinberg equilibrium in both groups. As shown in Table 2, SNPs rs3077 GG genotype in HLA-DPA1 and rs9277535 GG genotype in HLA-DPB1 were significantly associated with HBV infection after adjustment by sex, age, $\mathrm{HBV}$ vaccination, HBIG treatment, maternal HBV infection status, delivery mode and feeding patterns $(\mathrm{OR}=1.584,95 \%$ $\mathrm{CI}=1.012-2.480, \mathrm{P}=0.004 ; \mathrm{OR}=2.199,95 \% \mathrm{CI}=1.389-3.480$, $\mathrm{P}=0.001$; respectively). The risk alleles of $\mathrm{G}$ were found in both SNPs, with ORs of 1.309 (95\% CI 1.046 to 1.639) and 1.411 (95\% CI 1.125 to 1.771 ), respectively.

We conducted a genetic model analysis among the seven SNPs and the results are presented in Table 3. Four genetic models were applied in this study. The dominant model: the risk genotype GG was identified in both rs3077 and rs9277535, with ORs of 1.724 (95\% CI 1.105 to 2.691) and 2.484 (95\% CI 1.577 to 3.913), respectively. The overdominant model: the genotype GA in rs9277535 was found to be a protective factor for $\mathrm{HBV}$ infection in children (OR = $0.076,95 \%$ CI 0.010 - 0.583). In addition, the rs2281388 GA and rs9366816 TC genotypes were correlated with HBV susceptibility, respectively ( $\mathrm{rs} 2281388, \mathrm{OR}=1.422,95 \% \mathrm{CI} 1.032-$ 1.961; rs9366816, OR $=1.444,95 \% \mathrm{CI} 1.045$-1.994). Finally, the codominant model: the rs9277535 AA genotype and rs3077 AA genotype were still found to be significantly different between cases and controls $(\mathrm{P}=0.044, \mathrm{P}=0.001)$. Only the rs9277535 genotype was observed to be significantly different in recessive model analysis (OR $=1.752,95 \%$ CI 1.123 2.735).

\subsection{Relation of the SNPs and HBV Breakthrough Risk in Children}

We further explored the association of those SNPs at HLA loci and HBV breakthrough infection in children who were born to HBsAg-positive mothers. As shown in Table 4 , after adjustment by age, sex, delivery mode and feeding patterns, genotype GA in rs9277535 in HLA-DPB1 was also identified to be significantly associated with HBV breakthrough infection in the children whose mothers were positive for HBsAg $(\mathrm{OR}=0.098,95 \%$ CI 0.013-0.770, $\mathrm{P}=0.027)$.

\section{Discussion}

In this study, we investigated polymorphisms in HLA$D P$ and $H L A-D Q$ genes for HBV infection susceptibility in children. Our study firstly pointed out that four SNPs (HLA-DPA1 rs3077, HLA-DPB1 rs9277535, rs2281388 and HLADPB2 rs9366816) were significantly associated with HBV infection in children. Accumulating evidence has demonstrated that $H L A-D P / D Q$ variants were associated with $\mathrm{HBV}$ infection in adults. Mbarek et al. reported that genetic variants in HLA-DQ loci (rs2856718 and rs7453920) were strongly related to HBV infection in the Japanese population (9), which was also confirmed in the Korean and Chinese Han populations $(10,12)$. However, neither of the two currently hot SNPs showed significant signals in our study in children. This is possibly explained by the fact that children's immune systems have not yet fully developed in comparison to those of adults, thus causing different immune mechanisms to address HBV infection.

A number of previous studies, including GWAS, found that SNPs (rs3077 and rs9277535) in the HLA-DP gene were highly associated with chronic HBV infection in Asians (8, $11,13,14)$. In our present study, there was a statistical difference in both allele $\mathrm{G}$ and genotype GG levels of the two SNPs when comparing patients with HBV infection and healthy children. This finding suggests that the rs3077 and rs9277535 major $G$ alleles are risk factors for HBV infection, which is consistent with the previous studies. O'Brien et al. found that rs3077 and rs9277535 were also strongly associated with the decreased mRNA expression of HLADPA1 and HLA-DPB1 respectively, indicating that lower expression of HLA-DPA1 and HLA-DPB1 is a factor for increased risk of chronic HBV infection (15), which shows that the expression of these genes is important for the control of HBV replication. However, whether the variants in HLA-DP are related to liver cirrhosis or HCC development remains to be seen. Liao et al. found that HLA-DP polymorphisms (rs3077 or rs9277535) were not associated with HCC development, but were related to HBV susceptibility and HBV natural clearance (13). Hu et al. demonstrated that a variant at rs9277534 in HLA-DPB1 could influence both the spontaneous clearance of $\mathrm{HBV}$ infection and progression from asymptomatic HBV carriers to HBV-related liver cirrhosis in the Southwest Han Chinese population (16).

Additionally, through genetic model analysis, our study found that rs9366816 (TT + CC versus TC) near HLADPB2 showed significant association with HBV infection in children. This finding was consistent with a previous study in male Han Taiwanese, which showed that rs9366816 is an independent contributor to HBV susceptibility (17). Zhang et al. reported that another SNP rs2281388 (GG + AA versus $\mathrm{GA}$ ) in HLA-DPB1 was statistically related to HBV infection in 
Table 1. General Characteristics of HBV-Infected Children and Control Children ${ }^{\mathrm{a}}$

\begin{tabular}{|c|c|c|c|}
\hline Variables & Cases, $n=274$ & Controls, $\mathrm{n}=353$ & P Value \\
\hline Sex, No. (\%) & & & 0.004 \\
\hline Male & $180(65.7)$ & $181(51.4)$ & \\
\hline Female & $94(34.3)$ & $171(48.6)$ & \\
\hline Age, month, mean $\pm S D$ & $73.9 \pm 48.3$ & $30.3 \pm 18.0$ & 0.000 \\
\hline HBV vaccination, No. (\%) & & & 0.000 \\
\hline Yes & $101(87.1)$ & $353(100)$ & \\
\hline No & $15(12.9)$ & $0(0)$ & \\
\hline HBIG, No. (\%) & & & 0.010 \\
\hline Yes & $47(52.2)$ & $132(37.4)$ & \\
\hline No & $43(47.8)$ & $221(62.6)$ & \\
\hline Delivery mode, No. (\%) & & & 0.001 \\
\hline Spontaneous delivery & $103(54.5)$ & $48(36.4)$ & \\
\hline Cesarean delivery & $86(45.5)$ & $84(63.6)$ & \\
\hline Feeding patterns, No. (\%) & & & 0.474 \\
\hline Breast feeding & $63(33.7)$ & $37(28.0)$ & \\
\hline Mixed feeding & $21(11.2)$ & $19(14.4)$ & \\
\hline Artificial feeding & $103(55.1)$ & $76(57.6)$ & \\
\hline HBsAg (+) mothers, No. (\%) & & & 0.000 \\
\hline $\operatorname{HBeAg}(+)$ & $44(48.9)$ & $37(28.0)$ & \\
\hline $\operatorname{HBeAg}(-)$ & $9(10.0)$ & $61(46.2)$ & \\
\hline Others & $37(41.1)$ & $34(25.8)$ & \\
\hline
\end{tabular}

Abbreviation: HBIG, hepatitis B immunoglobulin; SD, Standard deviation.

${ }^{\mathrm{a}} \mathrm{P}<0.05$ was considered significant.

genotype B of HBV-infected subjects (18).

A new finding identified in this study was that rs9277535 variants are still significantly related to HBV infection in children who were born to HBsAg-positive mothers. The children in our study were all born later than 2002 and were older than 6 months when China began the immunization program offering free $\mathrm{HB}$ vaccine to all neonates. Both routine $\mathrm{HB}$ vaccines and HBIG are recommended at birth for infants born to HBsAg-positive mothers. Mother-to-child transmission of HBV remains one of the main transmission routes in China and is also the cause of a rate of $5-10 \%$ immunoprophylaxis failure (19). High levels of maternal viral load and HBeAg titer might induce the vaccination failure $(20,21)$. Escape mutants in the "a" determinant region and $S$ gene of HBV might be associated with vaccination failure in some infants $(22,23)$. Such mutants could potentially escape neutralizing HBsAb and infect vaccinated persons. Recently, a study in Taiwan showed that immunized children who were born to genotype $\mathrm{C}$ mothers might have a higher rate of breakthrough infection than those who were born to genotype B mothers (24). The difference in the results mentioned above is possibly explained by the fact that the effect of host genetic variants in HBV infection was not taken into consideration. Family clustering analysis and twin studies showed that host genetic factors could explain 63 - 85\% of vaccine responses to hepatitis B virus (25). Yan et al. demonstrated that host genetic factors played a dominant role in determining HBV vaccination responses in infants (91\%), as compared with perinatal environmental factors (26). In addition, Komatsu et al. found that although HLA-DPA1 (rs3077) variants did not show statistical associations with early HBeAg seroconversion, they might increase the possibility of achieving early spontaneous $\mathrm{HBeAg}$ seroconversion in children (27). In our study, we identified that HLA-DPB1 rs9277535 was related to HBV breakthrough infection in children who were born to HBsAg-positive mothers. These genetic 
Table 2. Genotype Distribution in HLA Loci and Their Association with HBV Infection in Children

\begin{tabular}{|c|c|c|c|c|c|c|c|c|}
\hline Gene & SNP & Genotype & Cases, \% & Controls, $\%$ & Crude OR $(95 \% \mathrm{CI})$ & PValue & Adjusted OR (95\% CI) ${ }^{\mathbf{a}}$ & PValue $^{\mathbf{a}}$ \\
\hline \multirow[t]{6}{*}{ HLA-DPA1 } & rs3077 & & & & & & & \\
\hline & & AA & $132(48.2)$ & $186(53.6)$ & 1 & & 1 & \\
\hline & & GA & $0(0)$ & $9(2.6)$ & . & 0.999 & & 0.999 \\
\hline & & GG & $142(51.8)$ & $152(43.8)$ & $1.316(0.956-1.812)$ & 0.092 & $1.584(1.012-2.480)$ & 0.004 \\
\hline & & A & $264(48.2)$ & $381(54.9)$ & 1 & & & \\
\hline & & G & $284(51.8)$ & $313(45.1)$ & $1.309(1.046-1.639)$ & 0.019 & & \\
\hline \multirow[t]{6}{*}{ HLA-DPB1 } & rs2281388 & & & & & & & \\
\hline & & GG & $82(29.9)$ & $122(35.2)$ & 1 & & 1 & \\
\hline & & GA & $150(54.7)$ & $159(45.8)$ & $1.404(0.981-2.008)$ & 0.063 & $1.478(0.885-2.468)$ & 0.135 \\
\hline & & AA & $42(15.3)$ & $66(19.0)$ & $0.947(0.587-1.526)$ & 0.822 & $1.188(0.621-2.272)$ & 0.602 \\
\hline & & G & $314(57.3)$ & $403(58.1)$ & 1 & & & \\
\hline & & A & $234(42.7)$ & $291(41.9)$ & $1.032(0.823-1.295)$ & 0.785 & & \\
\hline \multirow{6}{*}{ HLA-DPB1 } & rs3135021 & & & & & & & \\
\hline & & GG & $167(60.9)$ & $227(65.6)$ & 1 & & 1 & \\
\hline & & GA & $97(35.4)$ & $104(30.1)$ & $1.268(0.901-1.783)$ & 0.173 & $0.893(0.546-1.462)$ & 0.654 \\
\hline & & $\mathrm{AA}$ & $10(3.6)$ & $15(4.3)$ & $0.906(0.397-2.067)$ & 0.815 & $1.026(0.333-3.166)$ & 0.964 \\
\hline & & G & $431(78.6)$ & $558(80.6)$ & 1 & & & \\
\hline & & A & $117(21.4)$ & $134(19.4)$ & $1.130(0.856-1.493)$ & 0.387 & & \\
\hline \multirow[t]{6}{*}{ HLA-DPB1 } & rs9277535 & & & & & & & \\
\hline & & AA & $149(54.4)$ & $212(60.1)$ & 1 & & 1 & \\
\hline & & GA & $1(0.4)$ & $20(5.7)$ & $0.071(0.009-0.536)$ & 0.010 & $0.108(0.014-0.834)$ & 0.033 \\
\hline & & GG & $124(45.3)$ & $121(34.3)$ & $1.458(1.052-2.021)$ & 0.024 & $2.199(1.389-3.480)$ & 0.001 \\
\hline & & A & $299(54.6)$ & $444(62.9)$ & 1 & & & \\
\hline & & G & $249(45.4)$ & $262(37.1)$ & $1.411(1.125-1.771)$ & 0.003 & & \\
\hline \multirow[t]{6}{*}{ HLA-DPB2 } & rs9366816 & & & & & & & \\
\hline & & TT & $60(21.9)$ & $94(27.1)$ & 1 & & 1 & \\
\hline & & TC & $161(58.8)$ & $172(49.6)$ & $1.466(0.994-2.163)$ & 0.054 & $1.480(0.851-2.575)$ & 0.165 \\
\hline & & CC & $53(19.3)$ & $81(23.3)$ & $1.025(0.638-1.647)$ & 0.918 & $1.077(0.551-2.107)$ & 0.828 \\
\hline & & $\mathrm{T}$ & $281(51.3)$ & $360(51.9)$ & 1 & & & \\
\hline & & c & $267(48.7)$ & $334(48.1)$ & $1.024(0.819-1.281)$ & 0.835 & & \\
\hline \multirow[t]{6}{*}{ HLA-DQB1 } & rs2856718 & & & & & & & \\
\hline & & TT & $177(64.6)$ & $231(66.6)$ & 1 & & 1 & \\
\hline & & TC & $60(21.9)$ & $66(19.0)$ & $1.186(0.795-1.771)$ & 0.403 & $1.135(0.655-1.966)$ & 0.653 \\
\hline & & CC & $37(13.5)$ & $50(14.4)$ & $0.966(0.605-1.542)$ & 0.884 & $0.898(0.463-1.741)$ & 0.751 \\
\hline & & $\mathrm{T}$ & $414(75.5)$ & $528(76.1)$ & 1 & & & \\
\hline & & c & $134(24.5)$ & $166(23.9)$ & $1.030(0.793-1.337)$ & 0.827 & & \\
\hline \multirow[t]{6}{*}{ HLA-DQB2 } & rs7453920 & & & & & & & \\
\hline & & GG & $232(84.7)$ & $293(83.7)$ & 1 & & 1 & \\
\hline & & GA & $39(14.2)$ & $53(15.1)$ & $0.929(0.594-1.454)$ & 0.784 & $0.776(0.408-1.474)$ & 0.438 \\
\hline & & $\mathrm{AA}$ & $3(1.1)$ & $4(1.1)$ & $0.947(0.210-4.274)$ & 0.944 & $0.443(0.045-4.364)$ & 0.485 \\
\hline & & G & $503(91.8)$ & $639(91.3)$ & 1 & & & \\
\hline & & A & $45(8.2)$ & $61(8.7)$ & $0.937(0.627-1.402)$ & 0.752 & & \\
\hline
\end{tabular}

Abbreviation: $\mathrm{CI}$, confidence interval; OR, odds ratio; SNP, single nucleotide polymorphism.
${ }^{\mathrm{T}}$ The P values and $\mathrm{OR}(95 \% \mathrm{CI})$ were calculated from logistic regression analyses adjusting for sex, age, $\mathrm{HBV}$ vaccination, HBIG treatment, maternal HBV infection status, delivery mode and feeding patterns.

variants might be a useful reminder when developing a new HB genomic vaccine to more adequately prevent the spread of HBV.

In conclusion, the genetic variants of four SNPs (rs3077, rs9277535, rs2281388 and rs9366816) in HLA-DPA1 and HLA-
DPB1 loci have significant associations with HBV infection and breakthrough in children. This study provides insight into $\mathrm{HBV}$ infection in children and is valuable for the targeted management of, and control strategies for, this disease. 
Table 3. Association Between SNPs and HBV Infection in Children Using Genetic Models

\begin{tabular}{|c|c|c|c|c|c|c|c|}
\hline Gene & SNP & Model & Genotype & Crude OR (95\% CI) & P Value & Adjusted OR $(95 \% \text { CI })^{a}$ & PValue $^{a}$ \\
\hline \multirow[t]{4}{*}{ HLA-DPA1 } & rs3077 & Dominant & $\mathrm{GA}+\mathrm{AA} / \mathrm{GG}$ & $1.380(1.004-1.897)$ & 0.047 & $1.724(1.105-2.691)$ & 0.016 \\
\hline & & Recessive & $\mathrm{AA} / \mathrm{GA}+\mathrm{GG}$ & $1.243(0.905-1.707)$ & 0.179 & $1.429(0.918-2.224)$ & 0.114 \\
\hline & & Overdominant & $\mathrm{GG}+\mathrm{AA} / \mathrm{GA}$ & - & 0.999 & - & 0.999 \\
\hline & & Codominant & GG/GA & - & 0.999 & - & 0.999 \\
\hline \multirow[t]{5}{*}{ HLA-DPB1 } & rs2281388 & Dominant & $\mathrm{GA}+\mathrm{AA} / \mathrm{GG}$ & $0.788(0.561-1.106)$ & 0.168 & $0.719(0.442-1.170)$ & 0.184 \\
\hline & & Recessive & $\mathrm{AA} / \mathrm{GA}+\mathrm{GG}$ & $1.297(0.849-1.983)$ & 0.228 & $1.074(0.614-1.878)$ & 0.802 \\
\hline & & Overdominant & $\mathrm{GG}+\mathrm{AA} / \mathrm{GA}$ & $1.430(1.041-1.966)$ & 0.027 & $1.422(1.032-1.961)$ & 0.032 \\
\hline & & Codominant & GG/GA & $1.404(0.981-2.008)$ & 0.063 & $1.481(0.881-2.492)$ & 0.139 \\
\hline & & & GG/AA & $0.947(0.587-1.526)$ & 0.822 & $1.172(0.614-2.237)$ & 0.630 \\
\hline \multirow{4}{*}{ HLA-DPB1 } & & Recessive & $\mathrm{AA} / \mathrm{GA}+\mathrm{GG}$ & $1.196(0.529-2.706)$ & 0.666 & $0.940(0.308-2.870)$ & 0.914 \\
\hline & & Overdominant & $\mathrm{GG}+\mathrm{AA} / \mathrm{GA}$ & $1.275(0.910-1.788)$ & 0.158 & $0.892(0.548-1.453)$ & 0.646 \\
\hline & & Codominant & GG/GA & $1.268(0.901-1.783)$ & 0.173 & $0.892(0.546-1.459)$ & 0.650 \\
\hline & & & GG/AA & $0.906(0.397-2.067)$ & 0.815 & $1.043(0.338-3.220)$ & 0.942 \\
\hline \multirow[t]{5}{*}{ HLA-DPB1 } & rs9277535 & Dominant & $\mathrm{GA}+\mathrm{AA} / \mathrm{GG}$ & $1.585(1.147-2.191)$ & 0.005 & $2.484(1.577-3.913)$ & 0.000 \\
\hline & & Recessive & $\mathrm{AA} / \mathrm{GA}+\mathrm{GG}$ & $1.261(0.917-1.736)$ & 0.154 & $1.752(1.123-2.735)$ & 0.013 \\
\hline & & Overdominant & $\mathrm{GG}+\mathrm{AA} / \mathrm{GA}$ & $0.061(0.008-0.457)$ & 0.000 & $0.076(0.010-0.583)$ & 0.013 \\
\hline & & Codominant & GG/GA & $0.049(0.006-0.369)$ & 0.003 & $0.053(0.007-0.421)$ & 0.005 \\
\hline & & & GG/AA & $0.686(0.495-0.951)$ & 0.024 & $0.454(0.287-0.720)$ & 0.001 \\
\hline \multirow[t]{4}{*}{ HLA-DPB2 } & rs9366816 & Dominant & $\mathrm{TC}+\mathrm{CC} / \mathrm{TT}$ & $0.755(0.520-1.094)$ & 0.137 & $0.740(0.435-1.259)$ & 0.267 \\
\hline & & Overdominant & $\mathrm{TT}+\mathrm{CC} / \mathrm{TC}$ & $1.450(1.053-1.996)$ & 0.023 & $1.444(1.045-1.994)$ & 0.026 \\
\hline & & Codominant & $\mathrm{TT} / \mathrm{TC}$ & $1.466(0.994-2.163)$ & 0.054 & $1.464(0.839-2.553)$ & 0.180 \\
\hline & & & $\mathrm{TT} / \mathrm{CC}$ & $1.025(0.638-1.647)$ & 0.918 & $1.078(0.552-2.106)$ & 0.827 \\
\hline \multirow[t]{5}{*}{ HLA-DQB1 } & rs2856718 & Dominant & $\mathrm{TC}+\mathrm{CC} / \mathrm{TT}$ & $0.916(0.657-1.279)$ & 0.607 & $0.967(0.608-1.536)$ & 0.885 \\
\hline & & Recessive & $\mathrm{CC} / \mathrm{TC}+\mathrm{TT}$ & $1.078(0.682-1.705)$ & 0.747 & $1.148(0.601-2.194)$ & 0.676 \\
\hline & & Overdominant & $\mathrm{TT}+\mathrm{CC} / \mathrm{TC}$ & $1.194(0.806-1.767)$ & 0.376 & $1.156(0.675-1.980)$ & 0.598 \\
\hline & & Codominant & $\mathrm{TT} / \mathrm{TC}$ & $1.186(0.795-1.771)$ & 0.403 & $1.135(0.655-1.967)$ & 0.651 \\
\hline & & & $\mathrm{TT} / \mathrm{CC}$ & $0.966(0.605-1.542)$ & 0.884 & $0.912(0.474-1.752)$ & 0.781 \\
\hline \multirow[t]{5}{*}{ HLA-DQB2 } & rs7453920 & Dominant & $\mathrm{GA}+\mathrm{AA} / \mathrm{GG}$ & $1.075(0.696-1.659)$ & 0.745 & $1.341(0.718-2.505)$ & 0.358 \\
\hline & & Recessive & $\mathrm{AA} / \mathrm{GA}+\mathrm{GG}$ & $1.044(0.232-4.705)$ & 0.955 & $2.163(0.220-21.260)$ & 0.508 \\
\hline & & Overdominant & $\mathrm{GG}+\mathrm{AA} / \mathrm{GA}$ & $0.930(0.594-1.455)$ & 0.751 & $0.7850 .414-1.491)$ & 0.460 \\
\hline & & Codominant & GG/GA & $0.929(0.594-1.454)$ & 0.784 & $0.776(0.409-1.474)$ & 0.439 \\
\hline & & & GG/AA & $0.947(0.210-4.274)$ & 0.944 & $0.467(0.048-4.575)$ & 0.513 \\
\hline
\end{tabular}

Abbeviation: CI, confidence interval; OR, odds ratio; SNP, single nucleotide polymorphism.

${ }^{\mathrm{a}}$ The P values and OR $(95 \% \mathrm{CI})$ were calculated from logistic regression analyses adjusting for sex, age, HBV vaccination, HBIG treatment, maternal HBV infection status, delivery mode and feeding patterns. 
Table 4. Association Between SNPs and Risk of HBV Breakthrough Infection in Children Born to HBsAg (+) Mothers

\begin{tabular}{|c|c|c|c|c|c|c|c|c|}
\hline Gene & SNP & Genotype & Cases, \% & Controls, \% & Crude OR $(95 \% \mathrm{CI})$ & PValue & Adjusted OR $(95 \% \mathrm{CI})^{\mathrm{a}}$ & PValue $^{\mathrm{a}}$ \\
\hline \multirow[t]{5}{*}{ HLA-DPA1 } & rs3077 & & & & & & & \\
\hline & & AA & $42(46.7)$ & $64(49.6)$ & 1 & & 1 & \\
\hline & & GG & $48(53.3)$ & $56(43.4)$ & $1.306(0.755-2.259)$ & 0.339 & $1.305(0.750-2.271)$ & 0.346 \\
\hline & & A & $84(46.7)$ & $137(53.1)$ & 1 & & & \\
\hline & & G & $96(53.3)$ & $121(46.9)$ & $1.294(0.884-1.895)$ & 0.185 & & \\
\hline \multirow[t]{6}{*}{ HLA-DPB1 } & rs2281388 & & & & & & & \\
\hline & & GG & $26(28.9)$ & $39(30.2)$ & 1 & & 1 & \\
\hline & & $\mathrm{GA}$ & $49(54.4)$ & $59(45.7)$ & $1.246(0.667-2.326)$ & 0.490 & $1.340(0.710-2.526)$ & 0.366 \\
\hline & & AA & $15(16.7)$ & $31(24.0)$ & $0.726(0.329-1.601)$ & 0.427 & $0.808(0.361-1.805)$ & 0.602 \\
\hline & & G & $101(56.1)$ & $137(53.1)$ & 1 & & & \\
\hline & & A & $79(43.9)$ & $121(46.9)$ & $0.886(0.604-1.298)$ & 0.534 & & \\
\hline \multirow[t]{5}{*}{ HLA-DPB1 } & rs3135021 & & & & & & & \\
\hline & & $\mathrm{GA}$ & $25(27.8)$ & $38(29.7)$ & $0.938(0.514-1.712)$ & 0.836 & $0.902(0.491-1.659)$ & 0.741 \\
\hline & & $\mathrm{AA}$ & $4(4.4)$ & $3(2.3)$ & $1.902(0.411-8.802)$ & 0.411 & $1.588(0.337-7.479)$ & 0.558 \\
\hline & & G & $147(81.7)$ & $212(82.8)$ & 1 & & & \\
\hline & & A & $33(18.3)$ & $44(17.2)$ & $1.082(0.657-1.780)$ & 0.757 & & \\
\hline \multirow[t]{6}{*}{ HLA-DPB1 } & rs9277535 & & & & & & & \\
\hline & & AA & $46(51.1)$ & $72(54.5)$ & 1 & & 1 & \\
\hline & & GA & $1(1.1)$ & $19(14.4)$ & $0.082(0.011-0.636)$ & 0.017 & $0.098(0.013-0.770)$ & 0.027 \\
\hline & & GG & $43(47.8)$ & $41(31.1)$ & $1.642(0.932-2.890)$ & 0.086 & $1.677(0.949-2.966)$ & 0.075 \\
\hline & & A & $93(51.7)$ & $163(61.7)$ & 1 & & & \\
\hline & & G & $87(48.3)$ & $101(38.3)$ & $1.510(1.029-2.215)$ & 0.035 & & \\
\hline \multirow[t]{4}{*}{ HLA-DPB2 } & rs9366816 & & & & & & & \\
\hline & & ТT & $19(21.9)$ & $30(23.3)$ & 1 & & 1 & \\
\hline & & $\mathrm{T}$ & $93(51.7)$ & $128(49.6)$ & 1 & & & \\
\hline & & c & $87(48.3)$ & $130(50.4)$ & $0.921(0.629-1.348)$ & 0.672 & & \\
\hline \multirow[t]{6}{*}{ HLA-DQB1 } & rs2856718 & & & & & & & \\
\hline & & TT & $55(61.1)$ & $87(67.4)$ & 1 & & 1 & \\
\hline & & TC & $23(25.6)$ & $24(18.6)$ & $1.516(0.780-2.945)$ & 0.220 & $1.151(0.773-2.970)$ & 0.227 \\
\hline & & $\mathrm{CC}$ & $12(13.3)$ & $18(14.0)$ & $1.055(0.472-2.358)$ & 0.897 & $0.946(0.417-2.144)$ & 0.894 \\
\hline & & $\mathrm{T}$ & $133(73.9)$ & $198(76.7)$ & 1 & & & \\
\hline & & c & $47(26.1)$ & $60(23.3)$ & $1.166(0.751-1.812)$ & 0.494 & & \\
\hline \multirow[t]{6}{*}{ HLA-DQB2 } & rs 7453920 & & & & & & & \\
\hline & & GG & $75(83.3)$ & $110(84.0)$ & 1 & & 1 & \\
\hline & & GA & $14(15.6)$ & $19(14.5)$ & $1.081(0.510-2.288)$ & 0.839 & $0.984(0.459-2.108)$ & 0.966 \\
\hline & & AA & $1(1.1)$ & $2(1.5)$ & $0.733(0.065-8.233)$ & 0.802 & $0.559(0.049-6.349)$ & 0.639 \\
\hline & & G & $164(91.1)$ & $239(91.2)$ & 1 & & & \\
\hline & & A & $16(8.9)$ & $23(8.8)$ & $1.014(0.520-1.978)$ & 0.968 & & \\
\hline
\end{tabular}

Abbreviation: $\mathrm{CI}$, confidence interval; SNP, single nucleotide polymorphism; OR, odds ratio.
$\mathrm{a}_{\text {The }} \mathrm{P}$ values and $\mathrm{OR}(95 \% \mathrm{CI})$ were calculated from logistic regression analyses adjusting for sex, age, HBV vaccination, HBIG treatment, delivery mode and feeding patterns 


\section{Footnotes}

Authors' Contribution: Jie Fan and Xin Huang contributed equally to this paper. Study concept and design: Li Zhou, Lihong Mu and Juan Chen; acquisition of data: Jie Fan, Xin Huang, Yiling Cai and Lin Xiong; analysis and interpretation of data: Jie Fan and Xin Huang; drafting of the manuscript: Jie Fan and Xin Huang; statistical analysis: Xin Huang and Li Zhou; study supervision: Lihong Mu and Juan Chen.

Funding/Support: This work was supported in part by the national natural scientific foundation of China (NSFC-81202274), funds for outstanding young scholars in Chongqing medical university were granted to LZ (CYYQ201304) and the Chongqing natural science foundation (cstc2014jcyjA10015).

\section{References}

1. WHO . Hepatitis B Media Centre no. 204. Geneva: World Health Organization; 2015.

2. McMahon BJ, Alward WL, Hall DB, Heyward WL, Bender TR, Francis DP, et al. Acute hepatitis B virus infection: relation of age to the clinical expression of disease and subsequent development of the carrier state. J Infect Dis. 1985;151(4):599-603. [PubMed: 3973412].

3. Lai CL, Ratziu V, Yuen MF, Poynard T. Viral hepatitis B. Lancet. 2003;362(9401):2089-94. doi: 10.1016/S0140-6736(03)15108-2. [PubMed: 14697813].

4. Russo FP, Rodriguez-Castro K, Scribano L, Gottardo G, Vanin V, Farinati F. Role of antiviral therapy in the natural history of hepatitis B virusrelated chronic liver disease. World J Hepatol. 2015;7(8):1097-104. doi: 10.4254/wjh.v7.i8.1097. [PubMed: 26052398]

5. Liang X, Bi S, Yang W, Wang L, Cui G, Cui F, et al. Epidemiological serosurvey of hepatitis $B$ in China-declining HBV prevalence due to hepatitis B vaccination. Vaccine. 2009;27(47):6550-7. doi: 10.1016/j.vaccine.2009.08.048. [PubMed: 19729084].

6. Xu ZY, Duan SC, Margolis HS, Purcell RH, Ou-Yang PY, Coleman PJ, et al. Long-term efficacy of active postexposure immunization of infants for prevention of hepatitis B virus infection. United StatesPeople's Republic of China Study Group on Hepatitis B. J Infect Dis. 1995;171(1):54-60. [PubMed: 7798683].

7. Zeng Z. Human genes involved in hepatitis B virus infection. World J Gastroenterol. 2014;20(24):7696-706. doi: 10.3748/wjg.v20.i24.7696. [PubMed: 24976707].

8. Kamatani Y, Wattanapokayakit S, Ochi H, Kawaguchi T, Takahashi A, Hosono N, et al. A genome-wide association study identifies variants in the HLA-DP locus associated with chronic hepatitis B in Asians. Nat Genet. 2009;41(5):591-5. doi:10.1038/ng.348. [PubMed: 19349983].

9. Mbarek H, Ochi H, Urabe Y, Kumar V, Kubo M, Hosono N, et al. A genome-wide association study of chronic hepatitis B identified novel risk locus in a Japanese population. Hum Mol Genet. 2011;20(19):3884-92. doi: 10.1093/hmg/ddr301. [PubMed: 21750111].

10. Hu Z, Liu Y, Zhai X, Dai J, Jin G, Wang L, et al. New loci associated with chronic hepatitis B virus infection in Han Chinese. Nat Genet. 2013;45(12):1499-503. doi: 10.1038/ng.2809. [PubMed: 24162738].

11. Guo X, Zhang Y, Li J, Ma J, Wei Z, Tan W, et al. Strong influence of human leukocyte antigen (HLA)-DP gene variants on development of persistent chronic hepatitis B virus carriers in the Han Chinese population. Hepatology. 2011;53(2):422-8. doi:10.1002/hep.24048. [PubMed: 21274863].
12. Kim YJ, Kim HY, Lee JH, Yu SJ, Yoon JH, Lee HS, et al. A genomewide association study identified new variants associated with the risk of chronic hepatitis B. Hum Mol Genet. 2013;22(20):4233-8. doi 10.1093/hmg/ddt266. [PubMed: 23760081].

13. Liao Y, Cai B, Li Y, Chen J, Tao C, Huang H, et al. Association of HLADP/DQ and STAT4 polymorphisms with HBV infection outcomes and a mini meta-analysis. PLoS One. 2014;9(11):111677. doi: 10.1371/journal.pone.0111677. [PubMed: 25365208].

14. Posuwan N, Payungporn S, Tangkijvanich P, Ogawa S, Murakami S, Iijima $S$, et al. Genetic association of human leukocyte antigens with chronicity or resolution of hepatitis B infection in thai population. PLoS One. 2014;9(1):86007. doi: 10.1371/journal.pone.0086007. [PubMed: 24465836].

15. O’Brien TR, Kohaar I, Pfeiffer RM, Maeder D, Yeager M, Schadt EE, et al. Risk alleles for chronic hepatitis B are associated with decreased mRNA expression of HLA-DPA1 and HLA-DPB1 in normal human liver. Genes Immun. 2011;12(6):428-33. doi: 10.1038/gene.2011.11. [PubMed: 21346778].

16. Hu Z, Yang J, Xiong G, Shi H, Yuan Y, Fan L, et al. HLA-DPB1 Variant Effect on Hepatitis B Virus Clearance and Liver Cirrhosis Development Among Southwest Chinese Population. Hepat Mon. 2014;14(8):19747. doi: 10.5812/hepatmon.19747. [PubMed: 25337146].

17. Chang SW, Fann CS, Su WH, Wang YC, Weng CC, Yu CJ, et al. A genomewide association study on chronic HBV infection and its clinical progression in male Han-Taiwanese. PLoS One. 2014;9(6):99724. doi: 10.1371/journal.pone.0099724. [PubMed: 24940741].

18. Zhang Q, Yin J, Zhang Y, Deng Y,Ji X, Du Y, et al. HLA-DP polymorphisms affect the outcomes of chronic hepatitis B virus infections, possibly through interacting with viral mutations.JVirol. 2013;87(22):12176-86. doi: 10.1128/JVI.02073-13. [PubMed: 24006435].

19. Luo Z, Li L, Ruan B. Impact of the implementation of a vaccination strategy on hepatitis B virus infections in China over a 20-year period. Int J Infect Dis. 2012;16(2):82-8. doi: 10.1016/j.ijid.2011.10.009. [PubMed: 22178658].

20. Liu SL, Dong Y, Zhang L, Li MW, Wo JE, Lu LW, et al. Influence of HBV gene heterogeneity on the failure of immunization with HBV vaccines in eastern China. Arch Virol. 2009;154(3):437-43. doi 10.1007/s00705-009-0315-y. [PubMed: 19212700].

21. Wang Z, Zhang J, Yang H, Li X, Wen S, Guo Y, et al. Quantitative analysis of HBV DNA level and HBeAg titer in hepatitis B surface antigen positive mothers and their babies: HBeAg passage through the placenta and the rate of decay in babies.J Med Virol. 2003;71(3):360-6. doi: 10.1002/jmv.10493. [PubMed: 12966540].

22. Sa-Nguanmoo P, Tangkijvanich P, Tharmaphornpilas P, Rasdjarmrearnsook AO, Plianpanich S, Thawornsuk N, et al. Molecular analysis of hepatitis B virus associated with vaccine failure in infants and mothers: a case-control study in Thailand. J Med Virol. 2012;84(8):117785. doi: 10.1002/jmv.23260. [PubMed: 22711345].

23. Roche B, Roque-Afonso AM, Sebagh M, Delvart V, Duclos-Vallee JC, Castaing D, et al. Escape hepatitis B virus mutations in recipients of antibody to hepatitis B core antigen-positive liver grafts receiving hepatitis B immunoglobulins. Liver Transpl. 2010;16(7):885-94. doi 10.1002/lt.22084. [PubMed: 20583085].

24. Wen WH, Chen HL, Ni YH, Hsu HY, Kao JH, Hu FC, et al. Secular trend of the viral genotype distribution in children with chronic hepatitis B virus infection after universal infant immunization. Hepatology. 2011;53(2):429-36. doi:10.1002/hep.24061. [PubMed: 21274864].

25. Lin TM, Chen CJ, Wu MM, Yang CS, Chen JS, Lin CC, et al. Hepatitis B virus markers in Chinese twins. Anticancer Res. 1989;9(3):737-41. [PubMed: 2764519].

26. Yan K, Cai W, Cao F, Sun H, Chen S, Xu R, et al. Genetic effects have a dominant role on poor responses to infant vaccination to hepatitis $B$ virus. J Hum Genet. 2013;58(5):293-7. doi: 10.1038/jhg.2013.18. [PubMed: 23486340]. 
27. Komatsu H, Murakami J, Inui A, Tsunoda T, Sogo T, Fujisawa T. Association between single-nucleotide polymorphisms and early sponta- neous hepatitis B virus e antigen seroconversion in children. BMC Res Notes. 2014;7:789. doi: 10.1186/1756-0500-7-789. [PubMed: 25376093]. 